\title{
New approach of friction AIN ceramics metallization with the initial FEM verification
}

\author{
Robert Cacko ${ }^{1}\left[\right.$ · Tomasz Chmielewski ${ }^{1} \cdot$ Michał Hudycz ${ }^{1}$. Dariusz Golański ${ }^{1}$
}

Received: 12 February 2020 / Revised: 1 July 2020 / Accepted: 13 July 2020 / Published online: 23 July 2020

(c) The Author(s) 2020

\begin{abstract}
Although, the friction method is well known for metals surface modification, the novelty of the article is based on the new idea of ceramics surface treatment with metal. The paper describes AlN ceramic metallization process by titanium coating deposition, obtained in friction surfacing method, which has been developed by the authors. The friction energy is directly transformed into heat and delivered in a specified amount precisely to the joint being formed between the metallic layer and the ceramics substrate material. The stress and temperature fields (as factors promoting the formation of diffusion joints) induced in the joint during the metallization process were qualitatively determined with the finite element method analysis and these results were verified experimentally. Finally, obtained structures of the metallic coatings were investigated and the results are discussed in the paper. As a novelty it was found, that the conditions of frictional metallization can favour the formation of a coating-substrate bond based on diffusion phenomena and atomic bonds of the coating components with the components of the substrate, despite the fact that it happens for metal-ceramics pairs. This type of connection is usually associated with long-term heating/annealing in chamber furnaces, because for diffusion in a solid state the most effective factor is time and temperature. It was shown that other components of the chemical potential gradient, such as temperature gradient, gradient and stress level, load periodicity and configuration of pairs of elements with high chemical affinity may play an important role in friction metallization. As a result, the relatively short time of operation (friction) is compensated.
\end{abstract}

Keywords AlN ceramics $\cdot$ Metallization $\cdot$ Ceramic-metal joints $\cdot$ Finite element modeling $\cdot$ Friction surfacing

\section{Introduction}

In recent years, a progress in the development of advanced surface modification processes can be clearly seen. It mainly concerns metals, when traditional welding methods can be applied [1,2] or more advanced in-situ concepts [3, 4], but it became also important in the field of ceramic materials [5-8]. Still growing demand for ceramic-metallic coupling has inspired searching for new, efficient methods, enabling joining of various types of ceramics with metals. The application of ceramic materials in advanced industrial products often requires a metal/ceramic merging. The surface of the ceramics modification by metallization is a method to combine the essentially different properties of these materials. Barlak et al. $[9,10]$ examined ion implantation as a

Robert Cacko

r.cacko@wip.pw.edu.pl

1 Institute of Manufacturing Technologies, Warsaw University of Technology, Narbutta 85 str., 02-524 Warsaw, Poland pre-treatment procedure for AlN substrates used for direct bonding with $\mathrm{Cu}$ replacing the conventional process of thermal oxidation and discussed in terms of changes induced by the implanted ions. Sałaciński et al. [11] proposed a new method of applying titanium coatings on ceramic surfaces using special rotating brushes with titanium fibres and usage of a wider range of soldering materials was described. This advantageous solution gives a wettability to the ceramic surface by applying a durable titanium coating. Iwaszko et al. [12] presented research of friction modification by means of material stirring (FSP-friction stir processing) of the surface layer of the AZ91 magnesium alloy with $\mathrm{SiC}$ particles. The obtained results proved, that using the FSP technology to modify the surface layer of magnesium alloys with $\mathrm{SiC}$ particles is an effective and promising solution with a high application potential, which allows forming the material structure to a substantial extent. Chemielewski et al. [13, 14] presented results concerning metallization of ceramic materials using the friction-welding method in which the mechanism of the formation of a joint involves the kinetic 
energy of friction. The friction energy is directly transformed into heat and delivered in a specified amount precisely to the joint being formed between the metallic layer and the substrate material. The ceramic/metal joints are basically made by two methods. In the first one, materials are joined directly, but in such cases possible pairs of the materials are significantly limited. In this area, Chmielewski et al. [15] presented the experiments concerning a manufacturing process of $\mathrm{Mo}-\mathrm{Al}_{2} \mathrm{O}_{3}$ composite materials obtained by the hot pressing method to overcome the problem of brittleness as the main technical limitation on a wide use of advanced ceramic materials. Lee et al. [16] performed brazing joining of $\mathrm{Al}_{2} \mathrm{O}_{3}$-SUS304 with the conventional $\mathrm{Ag}-\mathrm{Cu}$ eutectic filler metal by applying the surface modification techniques. High current ion beam and IBAD were used for the alteration and metallization of ceramics surfaces. Nagel et al. [17] investigated ion beam mixing and radiation enhanced diffusion (RED) of several metal-ceramic interfaces, finding that mixing efficiencies for metal-ceramic systems are significantly lower than for metal-metal systems, in agreement with earlier measurements. Chmielewski et al. [18] presents the results concerning the formation of a 'barrier' layer on AlN ceramic during its joining with copper by the copper direct bonding (CDB) technique. The surface of the ceramic was modified with titanium, using various amounts of this active component.

Another method of ceramic/metal joints, more often used, is based on creating a thin metallic coating on the ceramics surface, which can be relatively easily joined with metals using conventional welding methods. Both solutions could give products of high quality, but the keyword is efficiency: they entail considerable costs and the technological process is complicated. It is mainly because of the fact, that it requires both high temperatures the entire volume of the ceramics must be heated and a protective vacuum or "wet" hydrogen atmosphere. Moreover, the degree of valuables is also influenced by the fact, that the process is time-consuming. The methods most frequently used in the industrial practice are powder metallurgy, active brazing, physical vapour deposition-PVD, chemical vapour deposition-CVD and impulse plasma deposition-IPD [19, 20]. Another applied pre-treatment method which consists of the activation of the ceramic surface is metal ion implantation $[9,10]$
The difficulties encountered in joining ceramics with metals are associated with the extreme differences between the properties of these materials, such as:

- lack of wettability of ceramics by metals and lack of interactions between them (the bonds in ceramics are ionic, covalent, and mixed, whereas in metals they are metallic);

- no mutual solubility;

- weak diffusion of metals into ceramics;

- differing crystallographic lattices;

- considerable difference between the melting temperatures;

- great differences in hardness, brittleness, heat conductivity, and thermal expansion coefficients.

The advanced diffusion-based processes suitable for joining ceramics and other materials with metals must be conducted at high temperatures in vacuum, require additional expensive chemical substances application and need significant time $[15,16]$. The mechanism of formation of a joint at the interface of two solid bodies can be considered in terms of the theory, based on the thermodynamic approach, which assumes that joining is the transition of a system composed of two components with the free surface energies $A$ and $B$ into a one-component system with a new interfacial surface energy $A-B$ (Fig. 1):

$w_{A-B}<w_{A}+w_{B}$.

When two solid bodies are to be joined, the sum of their free surface energies is greater than the free interfacial surface energy. Assuming that every system tends to achieve the minimum free energy, it can be expected that, theoretically, two surfaces brought to contact will join spontaneously. In reality such a situation, however, does not appear. The reason is, that it is not possible to bring any two surfaces as close one to another, that their atoms, in a sufficient number, will be separated by the distance comparable with the crystalline lattice parameters. The surfaces of metals are not smooth either in the atomic or micro-scale. Moreover, they are covered with
Fig. 1 Two-component system before and after joining

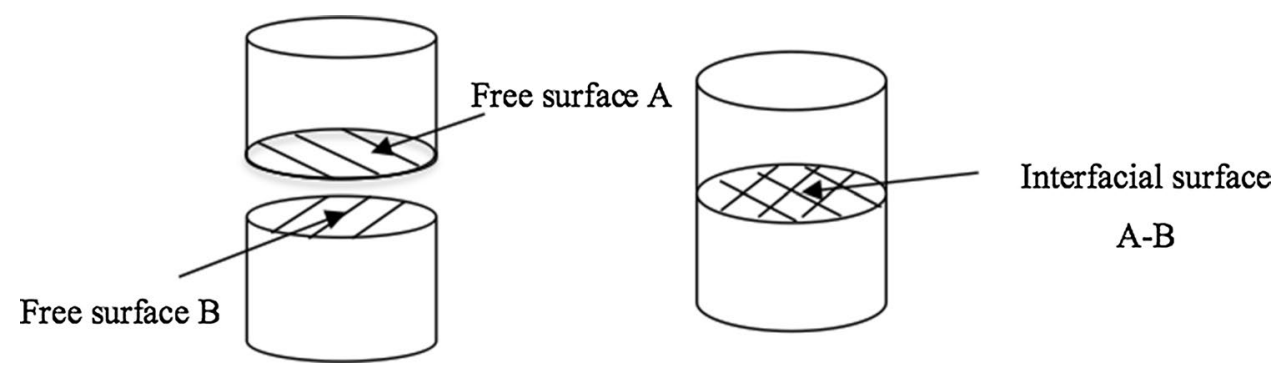


oxides, adsorbing vapours and gases, and also with various organic substances. In addition, it is necessary to deliver external energy to overcome the repulsive forces acting between the atoms on the free surface.

Assuming the thermodynamic approach, the joining process can be illustrated by the curve, as shown in Fig. 2. Point 1 represents the metastable state with the free enthalpy $G_{1}$, before joining, when the two surfaces are free. In point 2, the joint has already formed, and the free enthalpy $G_{2}$ is lower than $G_{1}$. The force which drives the transition from state 1 to state 2 is equal to the difference between the two free energies $\Delta G=G_{1}-G_{2}$. The transition from state 1 to state 2 requires overcoming the energy barrier $Q$, i.e., the activation energy must be delivered, so that the atoms of the two surfaces can be brought to a distance, where they strongly attract each other. In the joining practice, regardless of the mechanism of joint creation, the activation has the thermal character, i.e., an external source delivers heat necessary to increase the temperature to the melting or softening temperature. These phenomena are utilized in the friction method, described in the present paper, in which the required activation energy is delivered to the system in a mechanic way, by the transformation of kinetic energy into heat energy which is dissipated directly within the region of the joint being formed. These or similar mechanisms describing usage of the mechanical energy for enhancing the joining process have been already analysed. Some of them deal with friction welding $[21,22]$ or friction stir welding [23, 24], while others focus on different phenomena, e.g., vibrations tools activation in ultrasonic assisted joining/forming [25, 26].

\section{Friction surfacing concept}

In the technology proposed in the present paper, the required activation energy is delivered to the system in a mechanical way, utilizing the transformation of the energy of kinetic friction into heat directly in the region of the formation

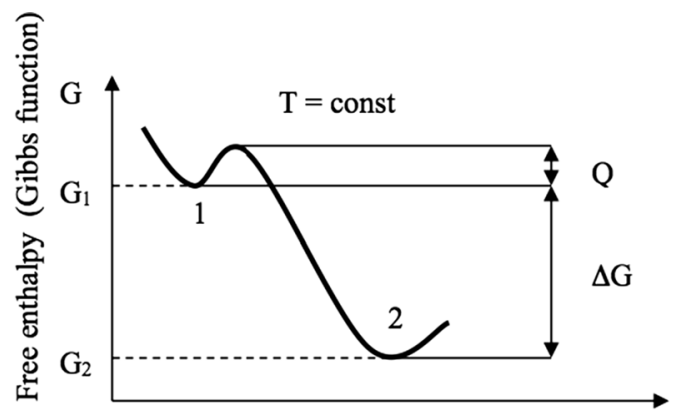

The progress of the process (e.g. number of atomic bonds)

Fig. 2 Variation of the free energy of the system being joined: (1) state before joining, (2) state after the formation of the joint of the joint. During the friction surfacing the coupling is formed when the metallic component reaches locally (in a relatively very short time) a temperature close to its melting point, and after that-again, very quickly cooled to room temperature. Therefore, the joining process should be considered to be solid-state joining with a substantial share of the energy of the kinetic friction. Contrary to already described methods used for joining ceramics with metals, mostly based on diffusion, in friction surfacing the temperature is delivered locally, there are no expensive additional chemically-active materials, and time to complete the process is significantly shorter. In diffusion-based methods the condition for a directed diffusion flux to be achieved is the existence of a gradient of chemical potential (Gibbs' mol free enthalpy), occurrence of which depends on the following factors:

- the chemical composition and structure of the material;

- kind and properties of the substrate material;

- ratio of the diameters of the matrix ions and the diffusing ions;

- corpuscular radiation;

- temperature;

- temperature gradient;

- kind and magnitude of the external load;

- deformation degree.

In the friction-driven metallization method proposed in the present paper the last three of the above mentioned factors are very favourable, since they have relatively high values and, thus, enable the process time to be significantly shortened.

The one of objectives of the study was to determine and analyse the distribution of temperature and stresses during the friction-based metallization of the AlN ceramics with titanium

\section{Experiment description}

Friction surfacing experiment involved the forehead surfaces of two elements, i.e., a titanium pipe-shape tool having an internal diameter of $3 \mathrm{~mm}$, external diameter of $9 \mathrm{~mm}$ and a height of $60 \mathrm{~mm}$ as well as a $4 \mathrm{~mm}$ thick AlN ceramic plate having a diameter of $20 \mathrm{~mm}$ (Fig. 3). The images of the obtained coating are shown in Fig. 4 . The objective of the friction process was to obtain a uniform metallised titanium thin coating on the ceramic surface. The process of friction-based metallisation consisted of the friction-induced heating of the titanium shape under a load of $13.4 \mathrm{MPa}$. The titanium pipe rotated at a rate of $2550 \mathrm{rev} / \mathrm{min}$, rubbing against the ceramic surface at a constant (independent of temperature) friction coefficient 
Fig. 3 Experimental stack-up: titanium tool—ceramic base: a general scheme, b laboratory tests

Fig. 4 Metallization coating: a macro-view of the surface, $\mathbf{b}$ SEM picture of substrate cross section of AlN-Ti coating system

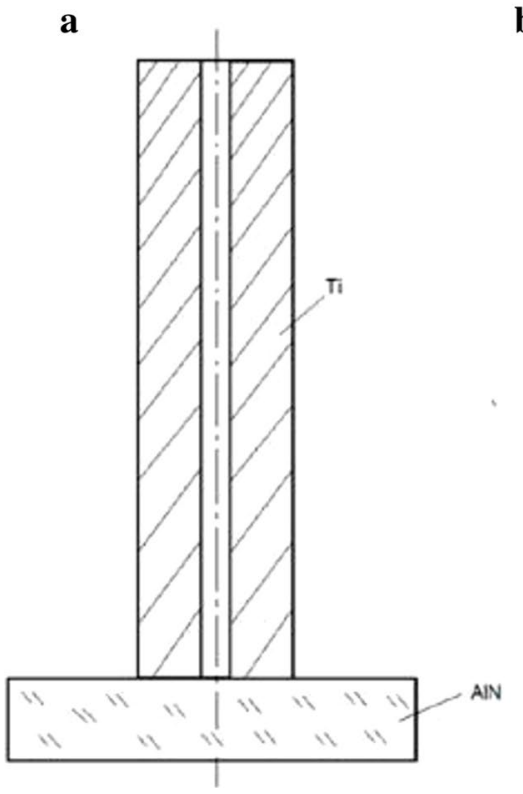

b

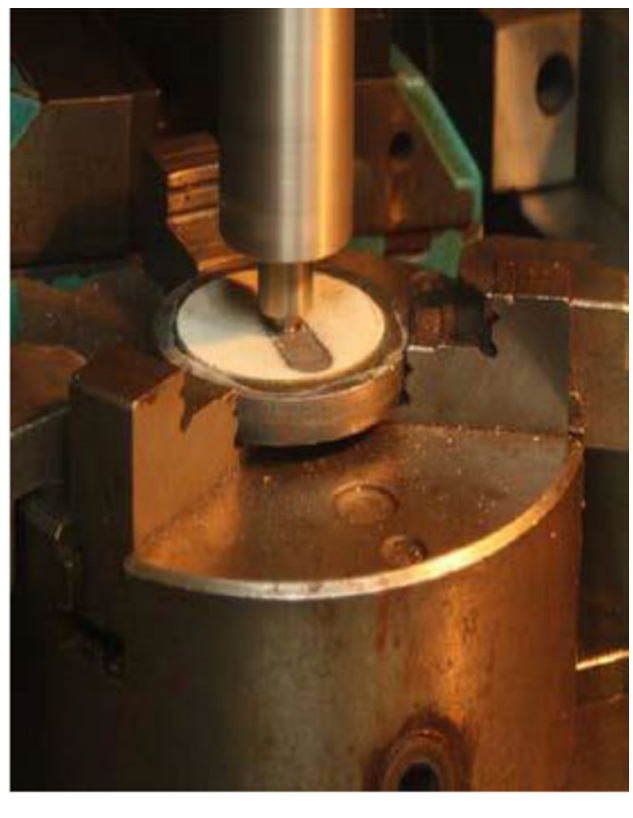

a

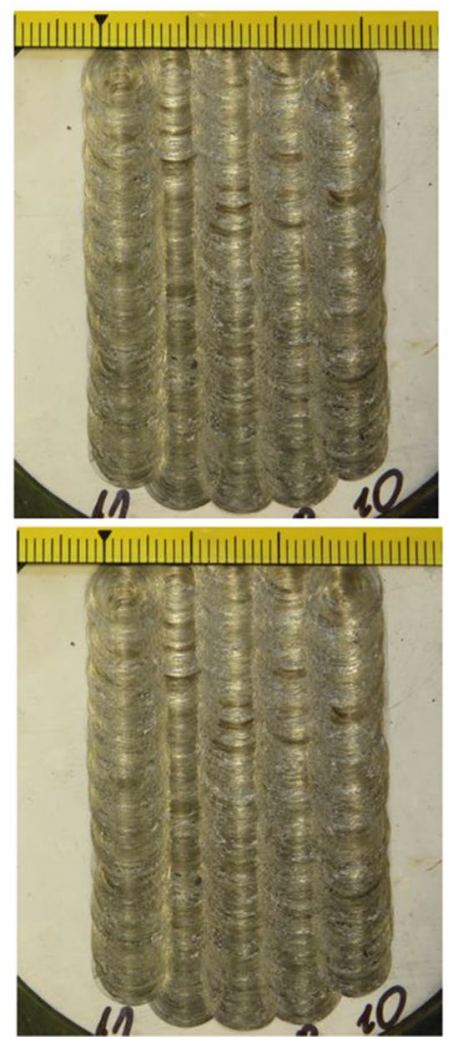

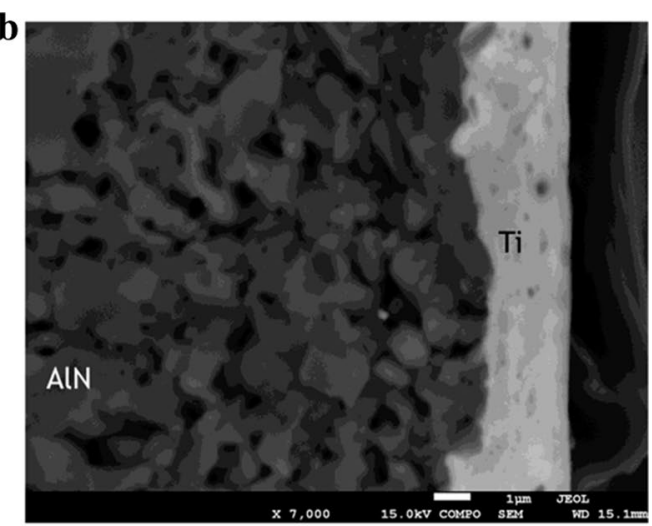

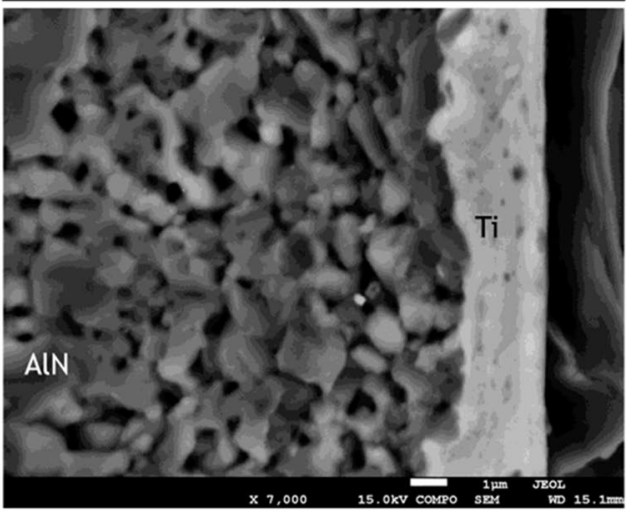

of 0.42 . The heating time was set to $14 \mathrm{~s}$, afterwards the tool started to move, rubbing its mass on the surface subjected to.

Translational movement of the tool along the ceramic surface was not taken into account. All these parameters were established on base initial experiments presented in Ref.
[27], were the mechanical properties and the phase structure of the surfaces obtained were also analysed.

Figure 4 shows the morphology of the fracture surface of the ceramic substrate (AIN) with the metallic coating (Ti). SEM images created with a BSE detector show mass contrast. Observations were made on the fracture surface 
obtained from a simple three-point bend test of the sample (stretching on the coating side), which is demanding and also involves a difficult qualitative test of adhesion between the coating and the substrate. No chipping was observed in the joint area.

The coating material was applied very well without discontinuities. It was bonded to the substrate and effectively filled the inequalities of the ceramic surface. The structure of the substrate shows the characteristics of AlN ceramics being a sinter of single grains with characteristic porosity. No cracks in ceramics substrate caused by frictional surfacing were observed. The coating thickness ranges from about 3-5 $\mu \mathrm{m}$. The titanium coating tightly covers the ceramic surface, and its thickness shows the inclusions of the submicrometric ceramic grains originating from the friction surface, the presence and distribution (as a markers) of which in the coating are stochastic and additionally confirm a high degree of yielding of the titanium grains during coating production.

\section{Computational model}

The purpose of numerical modeling was to determine and analyse the nature of the temperature and stresses distribution during the AlN friction metallization process of titanium. Because of the high dynamics of the metallization process and lack of access to the friction surface during the process, the measurement of stress and temperature values is practically impossible to achieve. The information collected from mathematical modeling refers to conditions and factors increasing the chemical potential gradient in the area of the new, emerging interfacial border, stimulating diffusion phenomena alternatively to high temperature maintained over a long period of time (as is the case with the classic ceramics metallization processes) in the area of the resulting connection between titanium ceramics coating and AlN substrate. Numerical analysis allowed to describe the nature of thermomechanical phenomena during the welding process, and also to provide supportive information for the analysis of the mechanism of formation the connection layer at the ceramic-metal interface.

Based on the parameters of the experimental stand, the numerical model has been defined. To determine the temperature and stresses fields the finite element method was selected, and two recognized FEM programs-Adina Thermal and Adina Structure-were applied. The problem has been treated as one-sidedly coupled. In mechanical fields modeling a contact on the face of the welded elements was applied, and in the modeling of temperature fields, the condition of uniform temperature on the frontal surfaces was imposed on both connected elements. The material properties both physical and mechanical variability in terms of temperature were taken into account. The problem was solved as non-linear, axisymmetric.

The numerical simulation of the friction process was performed in the cylindrical coordinate system $(r, \theta, z)$. The adoption of symmetry in relation to the axes of elements being friction surfaced resulted in the disappearance of coordinate $\theta$ in the description of the phenomena taking place during the process of friction. The simulation involved the use of axisymmetric, quadrangular, quadrinodal conductive $2 \mathrm{D}$ elements and bimodal, convective and radiation elements describing heat exchange at the edge of elements. The mesh of the model was composed of 1689 elements spread on 1787 nodes, and it was refined on the interface surface, basing on earlier works $[13,13,28]$. Figure 5 presents the model geometry used for solving the thermal problem over the finite-element mesh with marked boundary conditions: the loading with the heat flux $q$ on the interface surface as well as convection and radiation-based exchange of heat with the environment on the lateral cylindrical surfaces of the ceramic and titanium components. It was assumed that the temperature on the surfaces being in contact was uniform.

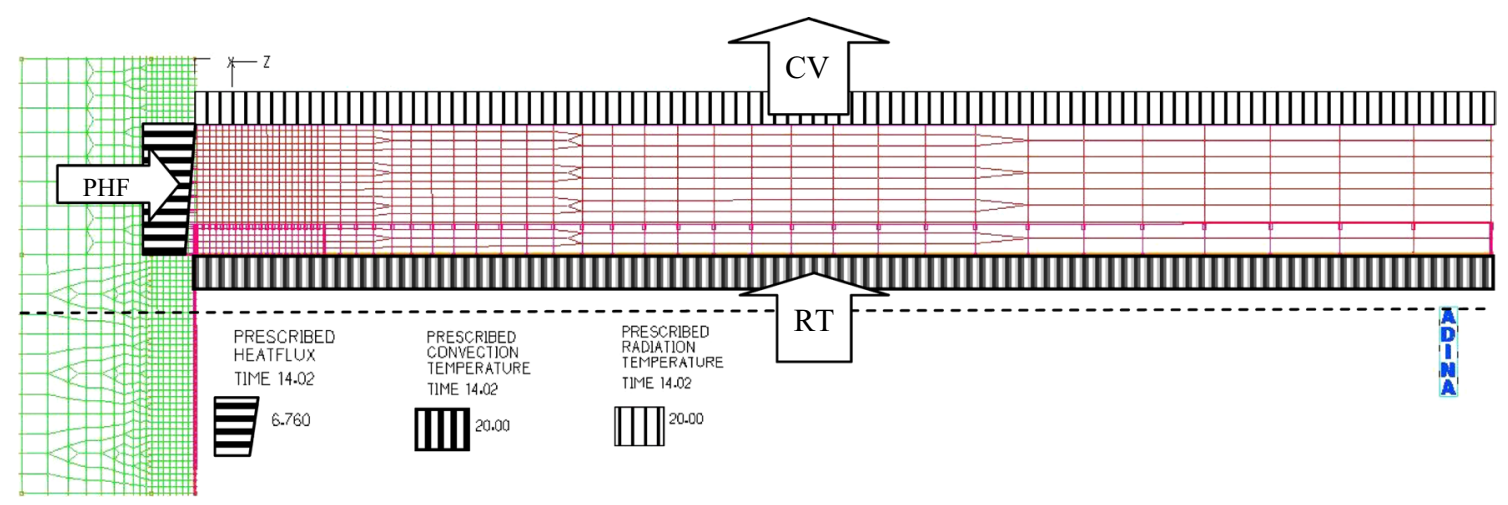

Fig. 5 Finite-element mesh of the AlN-Ti thermal model with boundary conditions—-prescribed heat flux—PHF, convection—CV, and radiation temperature-RT 
The heat flux q on the interface surface changed in a linear manner in accordance with the following dependence:

$q^{S^{k}}=\mu p_{n} V=\mu p_{n} \omega r$

where: $\mu$-friction coefficient, $p_{n}$-load affecting the friction surface, $\omega$-rate of rotation, $r$-radius.

The value of the heat flux calculated on internal radius $r_{1}=1.5 \mathrm{~mm}$ amounted to $q_{1}=2.46 \mathrm{~W} / \mathrm{mm}^{2}$, whereas on titanium tool internal radius $r_{2}=4.5 \mathrm{~mm}$ amounted to $q_{2}=6.76 \mathrm{~W} / \mathrm{mm}^{2}$. The calculations involved the adoption of the convection coefficient on rotating surfaces $\alpha_{\mathrm{k}}=40 \mathrm{~W} /$ $\mathrm{m}^{2} \mathrm{~K}$, on remaining surfaces $\alpha_{\mathrm{k}}=10 \mathrm{~W} / \mathrm{m}^{2} \mathrm{~K}$ and surface emissivity $\varepsilon=0.7$ [30-32].

For the purpose of simplifying the phenomena occurring during the friction process, it was assumed in numerical model that thermal and mechanical deformations considered for a given time increment would be treated as quasistatic. Thus, modeling of the friction process involves the imposition of a known temperature field (obtained from the solution of the thermal problem in subsequent time increments) on mechanical stress (set pressure $p_{i}$ in the friction phase for the same iterative steps). The mechanical model geometry was composed of the FEM mesh arranged in the same manner as in the thermal model, Fig. 6. The titanium material was described by the bilinear elastic-plastic model with Mises yield criteria and the AIN ceramic was described as an elastic material both having temperature dependent material properties up to $700{ }^{\circ} \mathrm{C}$, if the data were available. The material properties for AIN ceramic has been taken from [32-35] and the material properties of Titanium (grade 4) has been taken from Refs. [29, 32, 36]. The stress-strain curves for titanium up to $482{ }^{\circ} \mathrm{C}$ were taken from Ref. [37]. The titanium material was described using the bilinear elastic-plastic material model, and the parameters were based on earlier works [22], with the Young's modulus $E=129$ $050 \mathrm{MPa}$, yield point $R_{\mathrm{e}}=500 \mathrm{MPa}$ and hardening module $E_{\mathrm{u}}=500 \mathrm{MPa}$. The ceramics were described with the elastic material model with the Young's modulus $E=318200 \mathrm{MPa}$.

\section{Results analysis}

\subsection{Temperature distribution}

In Fig. 7, temperature field distributions during friction in subsequent times following the commencement of the welding of the AlN ceramics with titanium is presented. It is possible to notice an increase in temperature in the contact area, on the sides of both materials. The highest temperature reached approximately $1300{ }^{\circ} \mathrm{C}$ after $14 \mathrm{~s}$. Figure 8 presents radial distributions of temperature on the AlN ceramics side and on the titanium side in relation to selected heating times. It is easy to notice an increase in temperature in the friction line in the ceramics and higher values of temperature in the area adjacent to the titanium sleeve opening.

\subsection{Stresses distribution}

The mechanical analysis enabled to obtain distributions of all stress state components. Figures 9 and 10 contain maps of radial stresses $\sigma_{y y}$ at the final stage of friction as well as after releasing the load in the form of pressure affecting the specimens. As can be seen, the friction zone of the AlN ceramics was affected by high compressive stresses (up to $800 \mathrm{MPa}$ ) and not excessively high tensile stresses in titanium (up to $60 \mathrm{MPa}$ ), partly limited by the metal plastic strain. After releasing the load, radial stresses in the ceramics decreased by approximately $150 \mathrm{MPa}$.

The distributions of axial stresses $\sigma_{z z}$ are presented in Figs. 11 and 12, whereas that of circumferential stresses $\sigma_{y z}$ in Figs. 13 and 14. Neither of these components reaches high values (up to $100 \mathrm{MPa}$ ) at the final stages of friction or after releasing the load. In the process of a ceramic-metal joint formation, an important role is played by the interlayer. The time of friction-induced heating amounts to $14 \mathrm{~s}$, whereas at the final stage, the temperature on the interface surface reaches approximately $1300{ }^{\circ} \mathrm{C}$. In addition to temperature and time, the mechanism of

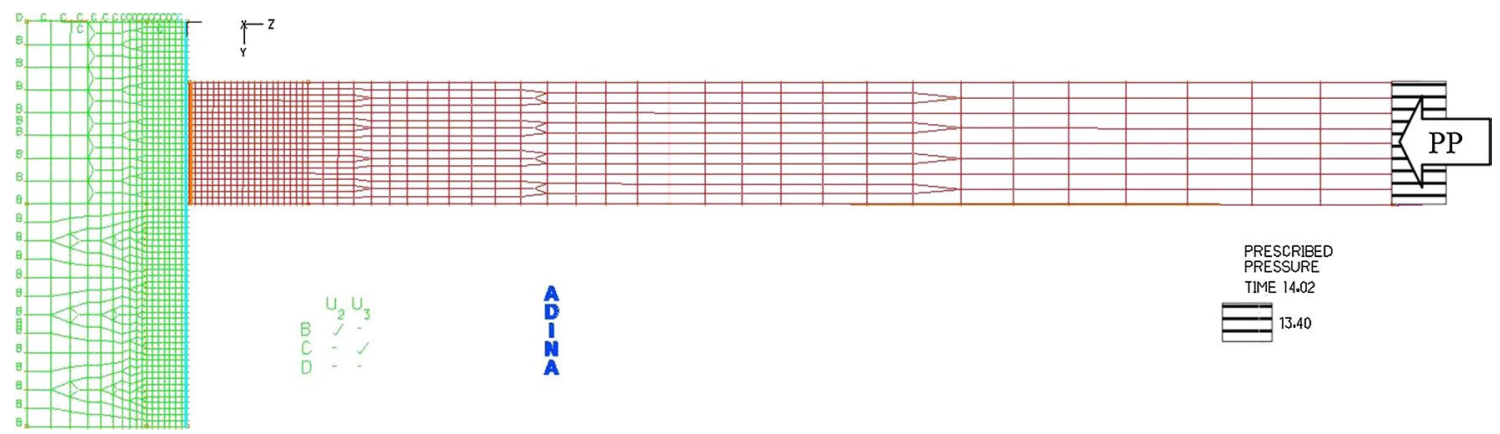

Fig. 6 Finite-element mesh of the AlN-Ti mechanical model with designated boundary conditions—prescribed pressure—PP 


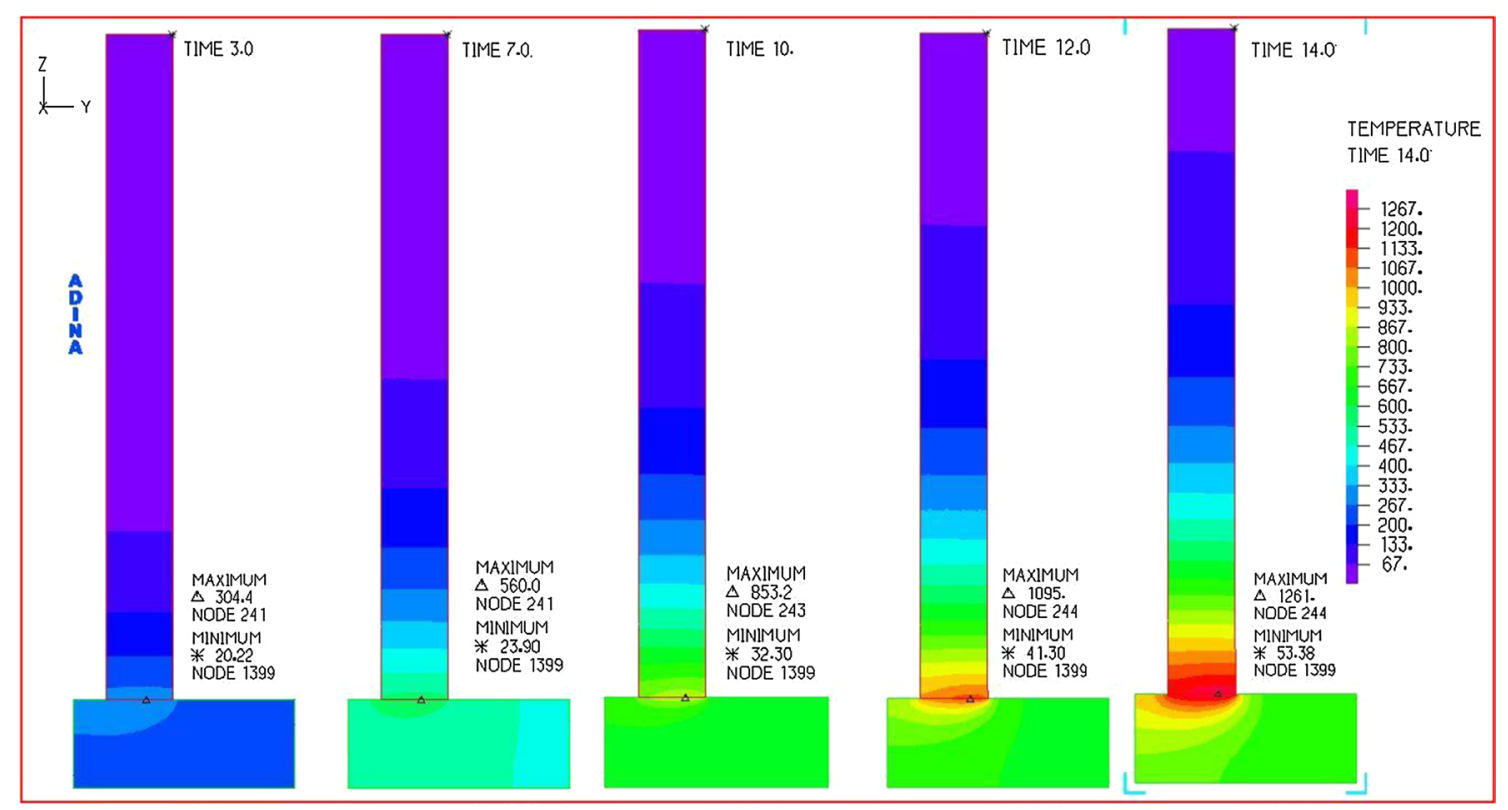

Fig. 7 Maps of temperature distribution for selected times of the friction-induced heating of the AlN ceramics with titanium
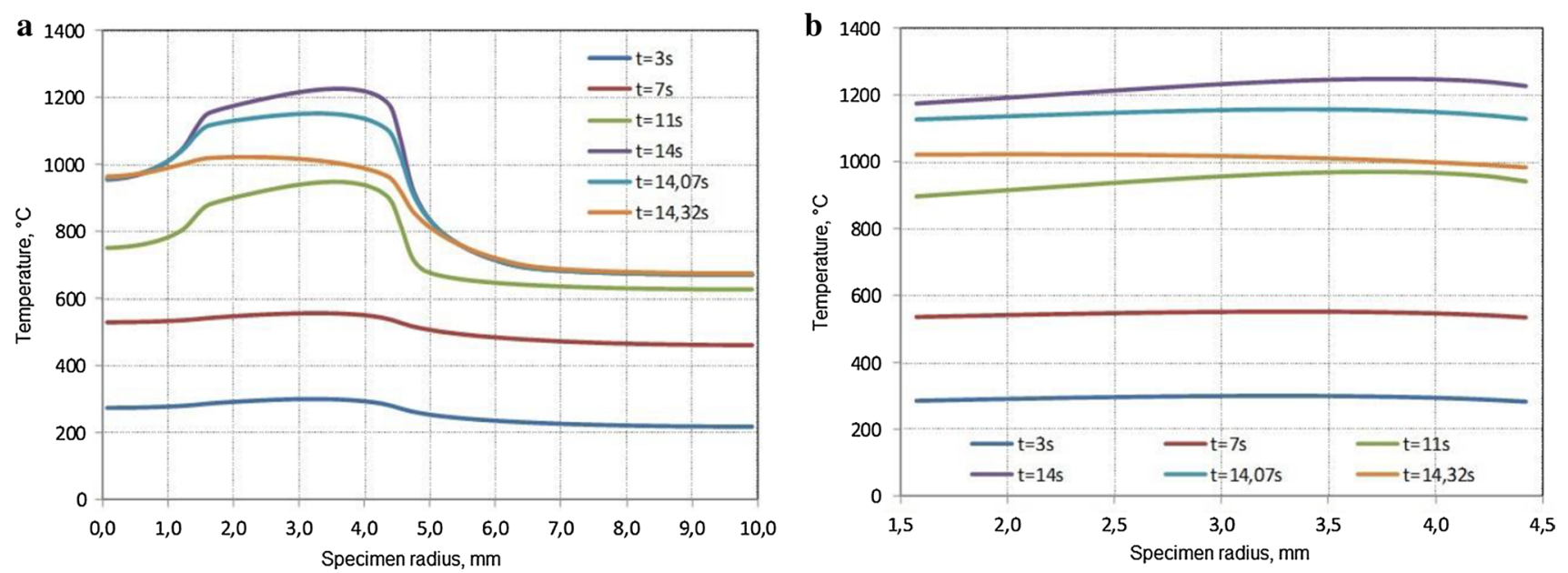

Fig. 8 Radial distributions of temperature on the AlN-Ti joint boundary: $\mathbf{a}$ on the AlN ceramics side, $\mathbf{b}$ on the titanium side

Fig. 9 Distribution of radial stresses $\sigma_{y y}$ near the interface surface at the final stage of friction-induced heating

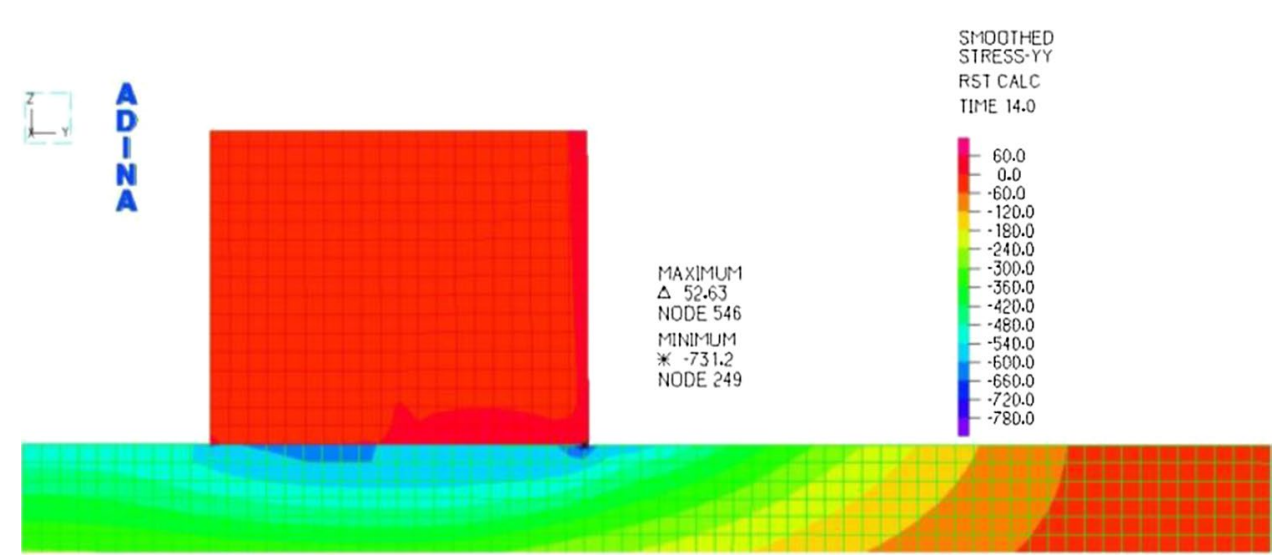


Fig. 10 Distribution of radial stresses $\sigma_{y y}$ near the interface surface after releasing the load and heat flux from friction $(0.32 \mathrm{~s})$
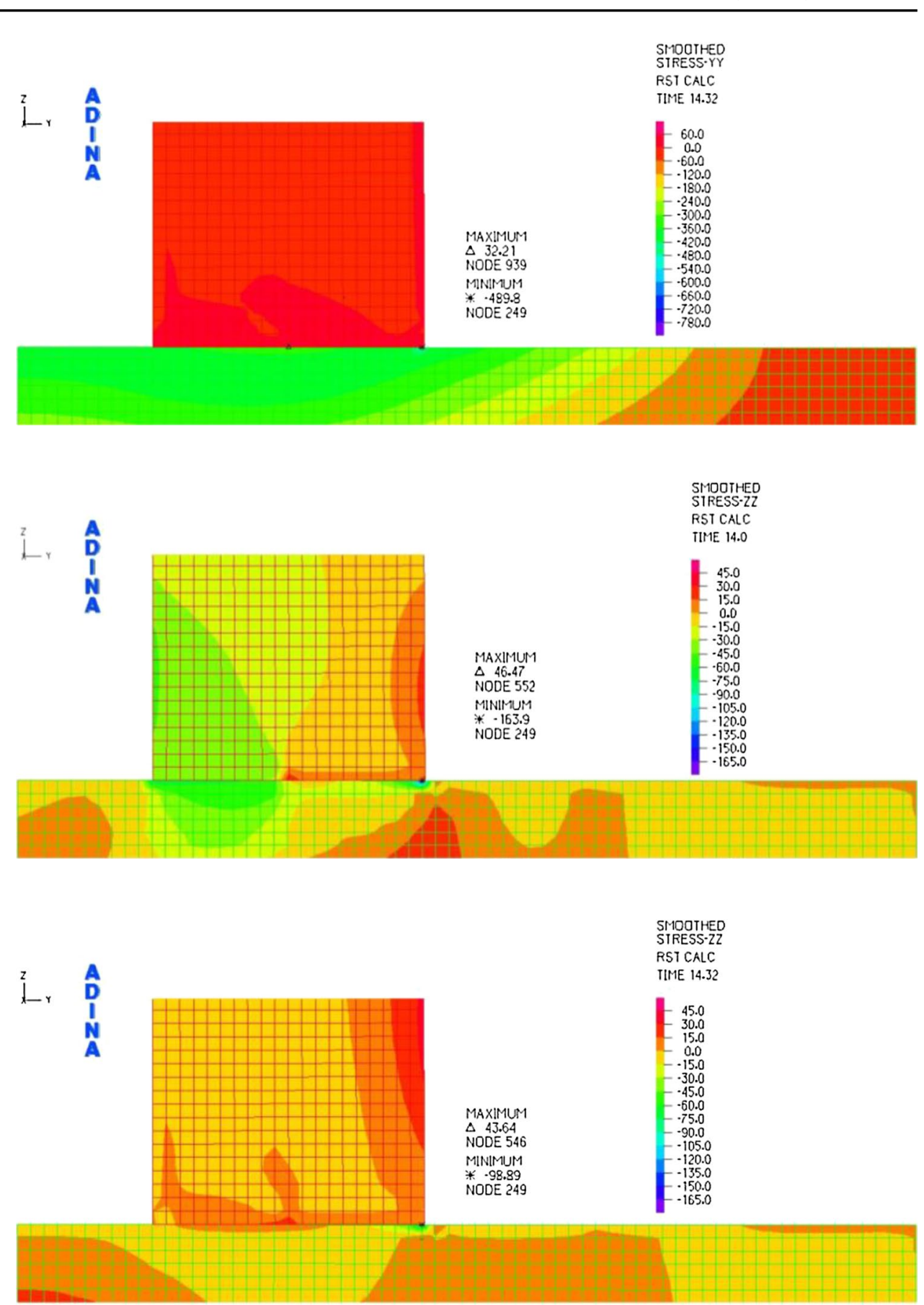

Fig. 12 Distribution of axial stresses $\sigma_{z z}$ near the interface surface at the final stage of friction-induced heating
Fig. 11 Distribution of axial stresses $\sigma_{z z}$ near the interface surface after releasing the load and heat stream from friction (0.32 s)

ic


Fig.13 Distribution of circumferential stresses $\sigma_{y z}$ near the interface surface at the final stage of friction-induced heating
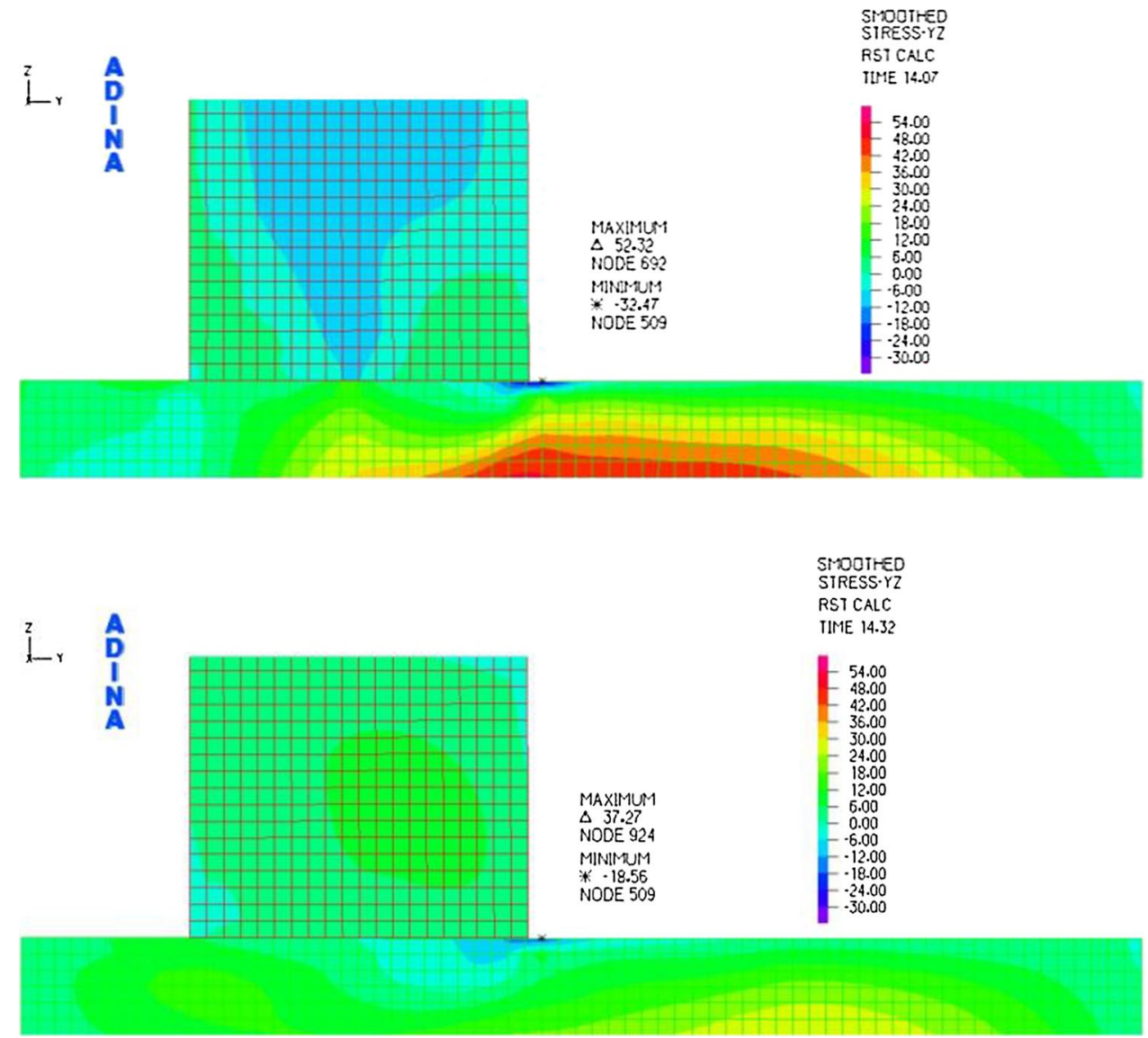

Fig. 14 Distribution of circumferential stresses $\sigma_{y z}$ near the interface surface after releasing the load and heat flux from friction $(0.32 \mathrm{~s})$

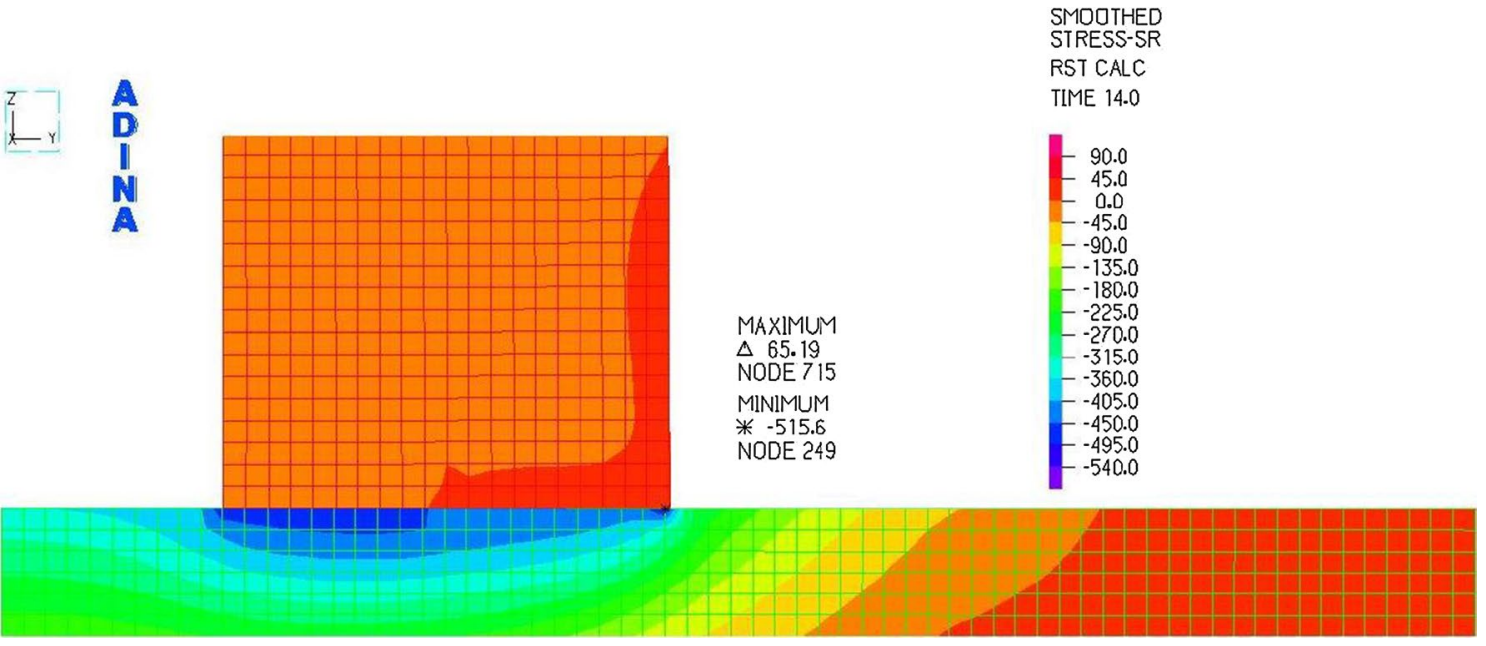

Fig. 15 Distribution of mean stresses $\sigma_{\mathrm{sr}}$ near the interface surface at the final stage of friction-induced heating

by low compressive axial stresses of approximately $6 \mathrm{MPa}$. This results from the significant deformations of the titanium shape in these areas and could affect the quality of the joint in these areas. On the AIN ceramics side, the stresses are restricted within the range of 40-100 MPa in the final phase of friction. The distributions of stresses in the boundary area, separately on the AlN side and on the titanium side are presented in Figs. 15 and 16. Attention should be paid to high compressive stresses in the ceramics and to the similar (in nature) distribution of mean stresses. 


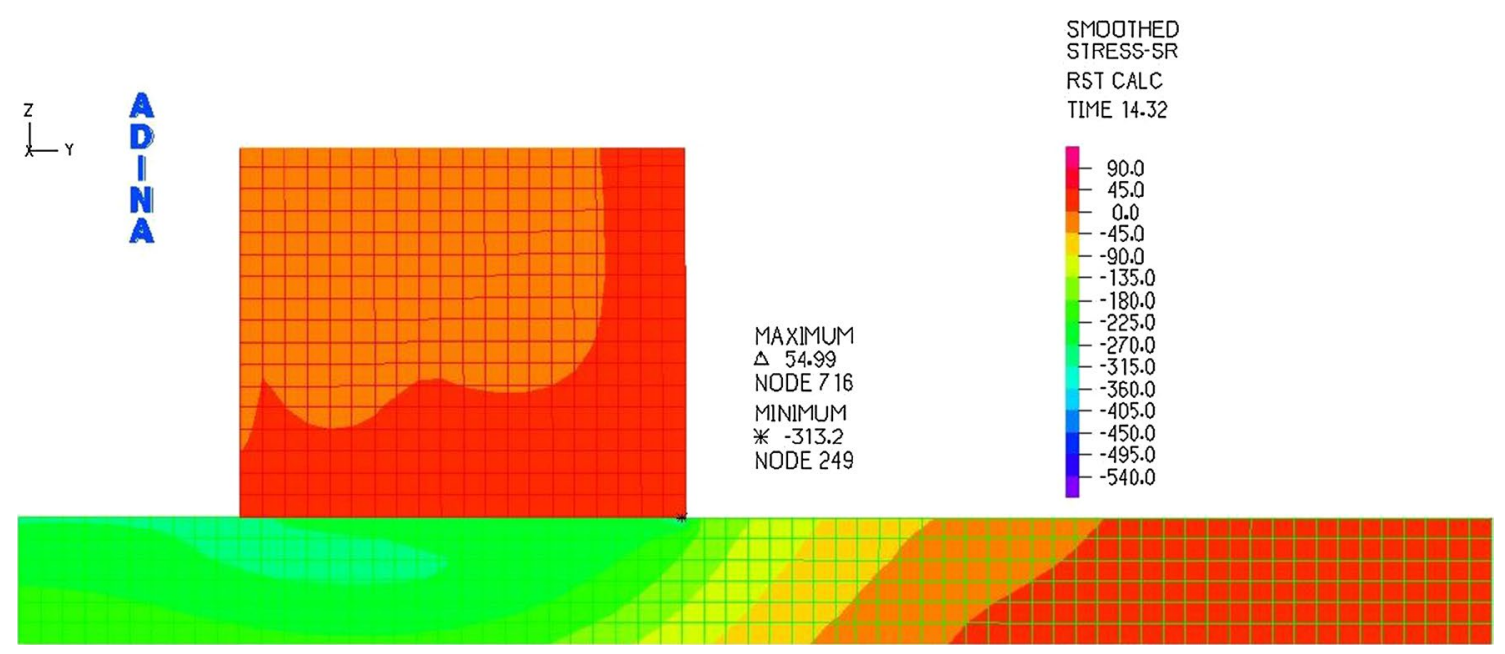

Fig. 16 Distribution of mean stresses $\sigma_{\text {sr }}$ near the interface surface after releasing the load and heat flux from friction $(0.32 \mathrm{~s})$

\section{Conclusions}

The numerical simulation of the friction metallisation of the AlN using titanium enabled the determination of temperature fields and distributions of stresses during the process of welding.

The calculations were limited to the friction zone; the solidification zone was ignored as it affected the generation of internal stresses and not the mechanism of joint formation. The performed calculations justified the following concluding remarks:

- distribution of temperature was non-uniform on the interface surface during the entire welding process; temperature in areas close to the axis was by approximately $200{ }^{\circ} \mathrm{C}$ lower than the maximum temperature amounting to $1300{ }^{\circ} \mathrm{C}$,

- the highest temperature was present on the interface and near it, i.e., within a radius of approximately $4 \mathrm{~mm}$ of the titanium cylinder-AlN base system,

- non-uniform distribution of axial compressive stresses near the interface surface, and increasing along with the time of friction, was caused by the significant deformation of the titanium tool material and could negatively affect the quality of coating,

- mean stresses (decisive for changes in volume) near the boundary surface, both on the ceramics and titanium side had negative values throughout the process of friction,

- releasing the load (0.05 s after the completion of welding) changed the value of mean stresses near the ceramics-titanium interface surface into positive.

It should be noted that presented numerical analysis results were approximate in nature because of a few simplifications assumed during the process of modeling, e.g., the lack of scientific references concerning the properties of titanium for the temperature range of $700 \div 1400{ }^{\circ} \mathrm{C}$, or the adopted friction coefficient on the ceramics-titanium interface (constant and independent of temperature). In addition, the simulations were performed using the constant heat flux generated from friction heat resulting from the supposed constant pressure on the contact interface. As a matter of fact, due to significant deformations of areas near the boundary surface, the pressure was variable in time. The performance of simulations with the heat flux variable in time requires numerous restarts of calculations, which, taking into consideration the substantially long heating time (14 s) could translate to time-consuming calculations and technical difficulties.

The presented results of the research and simulations indicate that thermodynamic conditions existing during friction metallization on ceramics promote ceramic/metals joint in solid state.

Open Access This article is licensed under a Creative Commons Attribution 4.0 International License, which permits use, sharing, adaptation, distribution and reproduction in any medium or format, as long as you give appropriate credit to the original author(s) and the source, provide a link to the Creative Commons licence, and indicate if changes were made. The images or other third party material in this article are included in the article's Creative Commons licence, unless indicated otherwise in a credit line to the material. If material is not included in the article's Creative Commons licence and your intended use is not permitted by statutory regulation or exceeds the permitted use, you will need to obtain permission directly from the copyright holder. To view a copy of this licence, visit http://creativecommons.org/licenses/by/4.0/. 


\section{References}

1. Świercz R, Oniszczuk-Świercz D. Experimental investigation of surface layer properties of high thermal conductivity tool steel after electrical discharge machining. Metals. 2017;7(12):550.

2. Górka J, Czupryński A. The properties and structure of arc sprayed coatings alloy of $\mathrm{Fe}-\mathrm{Cr}-\mathrm{Ti}-\mathrm{Si}-\mathrm{Mn}$. Int $\mathrm{J}$ Mod Manuf Technol. 2016;8(1):35-40.

3. Chmielewski T, Golański D. New method of in-situ fabrication of protective coatings based on $\mathrm{Fe}-\mathrm{Al}$ intermetallic compounds. Proc Inst Mech Eng J Eng Part B. 2011;225(4):611-6.

4. Morawiński $Ł$, Chmielewski T, Olejnik L, Buffa G, Campanella D, Fratini L. Welding abilities of UFG metals. AIP Conf Proc. 2018;1960(1):050012. https://doi.org/10.1063/1.5034885.

5. Czupryński A, Górka J, Adamiak M, Tomiczek B. Testing of flame sprayed $\mathrm{Al}_{2} \mathrm{O}_{3}$ matrix coatings containing $\mathrm{TiO}_{2}$. Arch Metall Mater. 2016;61(3):1363-70.

6. Pawlak A, Rosienkiewicz M, Chlebus E. Design of experiments approach in AZ31 powder selective laser melting process optimization. Arch Civ Mech Eng. 2017;17(1):9-18.

7. Strzelecka M, Iwaszko J, Malik M, Tomczyński S. Surface modification of the AZ91 magnesium alloy. Arch Civ Mech Eng. 2015;15(4):854-61.

8. Iwaszko J, Strzelecka M, Kudła K. Surface modification of the AZ91 magnesium alloy using GTAW technology. Bull Pol Acad Sci Tech Sci. 2017;65(6):917-26.

9. Barlak M, Olesińska W, Piekoszewski J, Chmielewski M, Jagielski J, Kaliński D, Werner Z, Sartowska B. Ion implantation as a pretreatment method of AlN substrate for direct bonding with copper. Vacuum. 2005;78(2-4):205-9.

10. Barlak M, Olesińska W, Piekoszewski J, Werner Z, Chmielewski M, Jagielski J, Kaliński D, Sartowska B, Borkowska K. Ion beam modification of ceramic component prior to formation of AlN-Cu joints by direct bonding process. Surf Coat Technol. 2007;201(19-20):8317-21.

11. Sałaciński T, Winiarski M, Przesmycki A, Świercz R, Chmielewski T (2018) Applying titanium coatings on ceramic surfaces by rotating brushes. In: Conference Proceedings, the 27th international conference on metallurgy and materials-metal 2018, pp 1235-1240.

12. Iwaszko J, Kudła K, Fila K. Friction stir processing of the AZ91 magnesium alloy with SiC particles. Arch Mater Sci Eng. 2016;77(2):85-92. https://doi.org/10.5604/18972764.1225604.

13. Chmielewski T, Golański D, Włosiński W, Zimmerman J. Utilizing the energy of kinetic friction for the metallization of ceramics. Bull Pol Acad Sci Tech Sci. 2015;2015(63):201-7.

14. Chmielewski T, Golański D, Włosiński W. Metallization of ceramic materials based on the kinetic energy of detonation waves. Bull Pol Acad Sci Tech Sci. 2015;63(2):449-56.

15. Chmielewski M, Dutkiewicz J, Kaliński D, Litynska-Dobrzynska L, Pietrzak K, Strojny-Nedza A. Microstructure and properties of hot-pressed molybdenum-alumina composites. Arch Metall Mater. 2012;57(3):687-93.

16. Kyu-Yong L, Won-Kyu H, In-Su J. Brazing joining of $\mathrm{Al}_{2} \mathrm{O}_{3}-$ SUS304 with surface modification method. In: Proceedings of the 3rd international brazing and soldering conference (ASM International) Texas USA, April, 24-26, 2006.

17. Nagel R, Hahn H, Balogh AG. Diffusion processes in metal/ ceramic interfaces under heavy ion irradiation. Nucl Instrum Methods Phys Res Sect B. 1999;148(1-4):930-5.

18. Olesińska W, Kaliński D, Chmielewski M, Diduszko R, Wlosiński $\mathrm{W}$. Influence of titanium on the formation of a "barrier" layer during joining an AlN ceramic with copper by the CDB technique. J Mater Sci Mater Electron. 2006;17(10):781-8.

19. Zhu S, Włosiński W. Joining of AlN ceramic to metals using sputtered Al or Ti film. J Mater Process Technol. 2001;109:277-82.

20. Zdunek K. Concept, techniques, deposition mechanism of impulse plasma deposition-a short review. Surf Coat Technol. 2007;201:4813-6.

21. Ambroziak A, Korzeniowski M, Kustroń P, Winnicki M. Friction welding of niobium and tungsten pseudoalloy joints. Int J Refract Met Hard Mater. 2011;29:499-504.

22. Zimmerman J, Włosiński W, Lindemann Z. Thermo-mechanical and diffusion modelling in the process of ceramic-metal friction welding. J Mater Process Technol. 2009;209:1644-53.

23. Malopheyev S, Mironov S, Kulitskiy V, Kaibyshev R. Friction-stir welding of ultra-fine grained sheets of $\mathrm{Al}-\mathrm{Mg}-\mathrm{Sc}-\mathrm{Zr}$ alloy. Mater Sci Eng A. 2015;624:132-21313.

24. Su J-Q, Nelson TW, Sterling CJ. Friction stir processing of largearea bulk UFG aluminum alloys. Scripta Mater. 2005;52:135-40.

25. Presz W, Cacko R. Ultrasonic assisted microforming. In: Conference Proceedings, the 26th international conference on metallurgy and materials-metal 2017, 2017, pp 521-526.

26. Presz W, Cacko R. Influence of micro-rivet manufacturing process on quality of micro-joint. AIP Conf Proc. 2011;1353:541-6.

27. Chmielewski T, Golański D, Hudycz M, Sałaciński T, Świercz R. Właściwości powierzchniowe i strukturalne tytanowej powłoki osadzanej tarciowo na podłożu ceramicznym AlN. Przemysł Chemiczny. 2019;2:1000-5. https://doi.org/10.15199 162.2019.2.XX.

28. Presz W, Cacko R. Determination of material distribution in heading process of small bimetallic bar. AIP Conf Proc 2018;1960:050014. https://doi.org/10.1063/1.5034887.

29. Boyer R, Welsch G, Collings E, editors. Materials property handbook: titanium alloys. Materials Park: ASM International; 1994.

30. Dorf RC, editor. Handbook of engineering tables. CRC Press LLC, Boca Raton; 2004.

31. Cronin DS, Bui K, Kaufmann C. Implementation and validation of the Johnson-Holmquist ceramic material model in LS-DYNA. In: Proceedings of the 4th European LS-DYNA User Conference (DYNAmore), 2003.

32. Goldsmith A, Waterman TE, Hirchorn HJ. Handbook of thermophysical properties of solid materials. New York: McMillan; 1961.

33. Slack GA, Bartram SF. Thermal expansion of some diamondlike crystals. J Appl Phys. 1975;46(1):89-988.

34. Slack GA, Tanzilli RA, Pohl RO, Vandersande JW. The intrinsic thermal conductivity of AIN. J Phys Chem Solids. 1987;48(7):641-7.

35. Koshchenko VI, Grinberg YK, Demidenko AF. Thermodynamic properties of AlN (5-2700 K), GaP (5-1500 K) and BP (5-800 K). Neorg Mater. 1984;20(11):1787-90.

36. Moosbrugger Ch, editor., Atlas of stress-strain curves, 2nd ed. Materials Park: ASM, 2002.

37. Bruls RJ, Hintzen HT, de With G, Metselaar R. The temperature dependence of the Young's modulus of MgSiN2, AlN and Si3N4. J Eur Ceram Soc. 2001;21(3):263-8.

Publisher's Note Springer Nature remains neutral with regard to jurisdictional claims in published maps and institutional affiliations. 